\title{
THE INFLUENCE OF PLANT GROWTH SATGE, INDIVIDUALS OF SPECIES, AND EXTRACTION METHODS ON THE ESSENTIAL OIL CONTENT AND THE CHEMICAL COMPOSITION OF PRANGOS FERULACEA (L.) LINDL
}

\author{
Mohebi, Z. ${ }^{1 *}-$ HeShmati, GH. A. ${ }^{1}-$ SefidKon, F. $^{2}-$ Zare Chahouki, M. A. ${ }^{3}$ \\ ${ }^{l}$ Department of Range Management, Faculty of Range and Watershed Management, Gorgan \\ University of Agricultural Sciences \& Natural Resources \\ Basij Sq., Gorgan, Golestan Province, Iran \\ ${ }^{2}$ Research Institute of Forests and Rangelands \\ P.O.Box: 13185-116, Tehran, Iran \\ ${ }^{3}$ Department of Rehabilitation of Arid and Mountainous Regions, Natural Resources Faculty \\ University of Tehran, P.O.Box: 31585-4314, Karaj, Iran \\ *Corresponding author \\ e-mail:za.mohebi@gmail.com
}

(Received $1^{\text {st }}$ May 2017; accepted $1^{\text {st }}$ Aug 2017)

\begin{abstract}
Prangos ferulacea is one of the species of essential oil plants, which is appreciated because of its value in medicine, perfumery, and forage industries. In order to gain the optimum oil yield of $P$. ferulacea, the essential oils of fertile and infertile individuals were isolated from the aerial parts by steam distillation and hydrodistillation methods at three maturity stages of pre-flowering, flowering, and seeding. The oils were analyzed by capillary GC (Gas Chromatography) and GC/MS (Gas Chromatography/Mass Spectroscopy). The extraction yields from the aerial parts of $P$. ferulacea were found to be $0.17 \%$ and $0.24-0.29 \%$ for steam distillation and hydrodistillation, respectively. The highest oil yield was obtained at the flowering stage in infertile individuals $(0.29 \% \mathrm{w} / \mathrm{w})$ for hydrodistillation. Thirty-four components, comprising $99.98 \%$ of the total oil, were identified at the flowering stage of infertile individuals, in which (E)-caryophyllene (48.21\%), $\alpha$-humulene (10.28\%), spathulenol $(9.36 \%)$, linalool $(3.46 \%)$, and $\delta$-3-carene $(3.37 \%)$ were recognized as the major components. Based on our findings, essential oil yields vary considerably from stage-to-stage and are also influenced by extraction methods. As well as, we found that infertile individual at the flowering stage can strongly enhance the quality of commercial oils in P. ferulacea.
\end{abstract}

Keywords: Prangos ferulacea, steam distillation, hydrodistillation, (E)-Caryophyllene, $\alpha$-Humulene, $\delta$-3Carene

\section{Introduction}

The genus Prangos consists of 30 species, 15 of which grow wild in many regions of Iran, and five are endemic (Mozaffarian, 1996). Prangos ferulacea (L.) Lindl. is found in the Balkans, Italy, Sicily, W. Syria, Caucasia, Turkey, and semi-arid regions of Iran (Rechinger, 1987; Ghahreman, 1997). This species is well-known for its economic importance in the form of various essential oils and for its high forage quality (Ayres et al., 1994; Sefidkon et al., 1998; Razavi, 2012).

The storage of essential oils in P. ferulacea is not restricted to specific parts of the plant. In fact, essential oils occur in roots, stems, leaves, flowers and seeds, or in the plant as a whole. Various compounds have been already identified in the oil of $P$. ferulacea. The number of components in the aerial parts and the seed is more than 30 
components according to Sefidkon and her colleagues (1998) and Razavi (2012). Moreover, 39 and 33 components were reported in the fruits (Massumi et al., 2007) and the roots (Sajjadi et al., 2011), respectively. Besides the applications in cosmetics, perfumes, and flavors, essential oils have been studied with regard to their antimicrobial properties (Eshbakova et al., 2006; Massumi et al., 2007), antioxidant properties (Razavi, 2012), hypoglycemic activities (Soltani band et al., 2011; Mohammadi and Zare, 2013), and antihyperlipidemic effects (Ramesh and Pugalendi, 2005).

Previous phytochemical studies on $P$. ferulacea (L.) Lindl. have indicated the presence of coumarin, alkaloid, flavonoid, and terpenoid derivatives. The performed investigations have reported the principal components in the leaves as follows: $\alpha$-pinene $(28.2 \%), \delta$-3-carene $(15.3 \%)$, limonene $(8.1 \%)$, and myrcene $(6.7 \%)$; and in the fruit oil: $\alpha$-pinene $(25.4 \%), 3$-n-butylphthalide $(13.8 \%)$, limonene $(10.6 \%), \delta$-3-carene $(9.1 \%)$, and sabinene $(8.1 \%)$; and in the roots, $\delta$-3-carene $(22.5 \%), \beta$-phellandrene $(11.8 \%), \alpha$ pinene $(8.6 \%)$, terpinolene $(7.2 \%)$, p-cymene $(6.3 \%), \alpha$-phellandrene $(6.2 \%)$, and myrcene $(4.5 \%)$.

Not only the ontogenesis, but also the intraspecific variation in particular (i.e., the differences between the individuals of an identical species), must be taken into account for the appropriate treatment of the plant samples, in order to determine the quality and variability of essential oil with regard to their composition. In general, P. ferulacea individuals annually seed 5 to 15 percent (Gheitori et al., 1997), and the biological properties of $P$. ferulacea show that it is polycarpic perennial (polycarpic plants flower and fruit more than once in their lifetimes) (Reuther, 2013). Thus, this species has both fertile and infertile individuals at different ranges.

It is worth stating that even though essential oils may be produced from an endemic population, but physiological and environmental factors as well as extraction methods may play an important role in the essential oil quality, purity, and origin, and also the composition of aromatic plants (Hay, 1993; Hay and Svoboda, 1993; Jordán et al., 2013; Sellami et al., 2012). The economic importance of $P$. ferulacea organic compounds in perfumery, food, medicine, and pharmaceutical industries, depends on the extract of the oil during the plant growth stages, which can consequently lead to increase the yield, quality, and purity of components (Ayres et al., 1994; Sefidkon et al., 1998; Coskun et al., 2004; Razavi, 2012).

Hydrodistillation and steam distillation methods can obtain essential oils from the plant material and induce thermal degradation, hydrolysis, and water solubilization of some fragrance constituents or solvent residues (Faborode, 1996). As a part of the biochemical studies at the Plant Biocentre, both techniques have been simultaneously utilized in the volatile analysis of essential oils in order to develop appropriate methods for different purposes.

The aim of the present work is the investigation of the effects of different maturity stages and types of individuals on the essential oil content and the chemical composition of Prangos ferulacea (L.) Lindl. For comparison purposes, the essential oils obtained by hydrodistillation and steam distillation were used. To the best of the authors' knowledge, no report has yet been accomplished on the comparison of the essential oil contents and the chemical components of fertile and infertile plants in P. ferulacea. 


\section{Materials and methods}

\section{Study Area}

This study was conducted in the Bistoon mountains of Kermanshah province in Iran (north-eastern slope at $34^{\circ} 27^{\prime} \mathrm{N}$ and $46^{\circ} 55^{\prime} \mathrm{E}$ ). The average annual temperature and annual rainfall are $11.88^{\circ} \mathrm{c}$ and $650 \mathrm{~mm}$ respectively that more precipitation is snow. At altitudes from 2200 to $2900 \mathrm{~m}$. the plant grows. The site soil is classified as a Regosolic. In the upper $5 \mathrm{~cm}$ of the site soil below the litter layer, total soil nitrogen, total soil phosphorus and potassium per unit soil volume are 0.46 (\%), 37.6 (p.p.m) and 610 (p.p.m) respectively.

\section{Plant materials}

During the annual growth, fertile and infertile plants grow together. First, at the preflowering stage, the aerial parts of fertile and infertile plants were cut on April, $12^{\text {th }}$ (stage 1). Then, at the flowering stage, the flowers appeared 42 days after leaf emergence on May, $6^{\text {th }}$ (stage 2). Finally, at the seeding stage, the seeds appeared 62 days after leaf emergence on June, $1^{\text {st }}$ (stage 3 ). They were cut regularly during May and June 2014 in a sample area of $50 \mathrm{~m}^{2}$ and randomly replicated three times. At each maturity stage, 36 plant samples were harvested at $10 \mathrm{~cm}$ above the ground level. The samples were then dried without conditioning and grounded in a laboratory mill, until they passed through a 1-mm-pore-size screen for chemical analysis.

\section{Hydrodistillation (HD) and steam distillation (SD)}

The dried plant materials (including fertile and infertile individuals) were submitted by hydrodistillation and using a Clevenger-type apparatus at each stage of the plant growth (i.e., the pre-flowering, flowering, and seeding stages). Distillation was performed by using approximately $100 \mathrm{~g}$ of each plant sample for 2 hours. In order to determine the composition of the oil and the contents at the flowering stage for infertile individuals, the aerial parts of the plant were subjected to hydrodistillation and steam distillation methods. The volatile distillates were collected over anhydrous sodium sulphate and stored in the refrigerator at $4{ }^{\circ} \mathrm{C}$ before the analysis. The oil yield was calculated as v/w of the dried plant material. Overall, three oil samples (3 replicates) were prepared from each type of plant, as described above.

\section{GC and GC/MS analyses}

GC analyses were performed using a Shimadzu GC- 9A gas chromatograph equipped with a FID and a DB-1 fused silica column $(60 \mathrm{~m} \cdot 0.25 \mathrm{~mm}$ i.d., film thickness 0.25 $\mathrm{lm})$. Oven temperature was programmed to $50 \mathrm{C}$ for $5 \mathrm{~min}$, and then increased to $250 \mathrm{C}$ at a rate of $4 \mathrm{C} / \mathrm{min}$. Injector and detector temperatures were 250 and $265 \mathrm{C}$, respectively. The carrier gas, helium, was adjusted to a linear velocity of $30 \mathrm{~cm} / \mathrm{s}$. The SFE samples (1 11) were injected into the GC (without any further dilution) using the split mode with a split ratio of 1/60. Hydrodistilled extracts were diluted 30 times and 1 11 of diluted solution was injected into the GC with the same split ratio. The GC/MS analysis was carried out on a Varian 3400 equipped with a DB-1 column with the same characteristics as the one used in GC. The transfer line temperature was $260 \mathrm{C}$. The ionization energy was $70 \mathrm{eV}$ with a scan time of $1 \mathrm{~s}$ and mass range of 40-300 amu. The percentages of compounds were calculated by the area normalization method, 
without considering response factors. The components of oil were identified by comparison of their mass spectra with those assembled via a Wiley 5 mass spectra computer library or with authentic compounds. Data obtained were confirmed by comparison of their retention indices, either with those of authentic compounds or with the data published in the literature (Adams, 2007).

\section{Statistical analysis}

The data on the composition of oils were calculated by analysis of variance (ANOVA) using SPSS software (version 19) (1993).

\section{Results and discussion}

Essential oils normally contain a complex mixture of organic compounds. They are largely composed of a range of saturated or partly unsaturated cyclic and linear molecules of relatively low molecular mass and within this range, a variety of hydrocarbons and oxygenated compounds occur. Various parameters, such as environmental and experimental conditions, physiological and ecological responses, growth rates, and productivity, potentially influence on the content and composition of oils. In this study, the main focus has been on the potential of extraction methods, the type of individuals, and the stage of maturity.

In total, thirty-four components were identified in the essential oil of P. ferulacea at the flowering stage for infertile individuals, representing $99.98 \%$ of the oil. The main components were (E)-caryophyllene $(48.21 \%), \alpha$-humulene $(10.28 \%)$, spathulenol (6.73\%), $\alpha$-bisabolol (4.25\%), and $\delta$-3-Carene (3.37\%) (Table 1$)$.

Table 1. The percentage composition of the essential oil obtained by hydro-distillation from Prangos ferulaceae ( $L$.) Lindl at flowering stage

\begin{tabular}{c|l|c|c|c|c}
\hline No. & & Compound & RI & $\begin{array}{c}\text { (\%) } \\
\text { Composition }\end{array}$ & $\begin{array}{c}\text { Mode of } \\
\text { identification }\end{array}$ \\
\hline 1 & $\alpha$-Thujene & & 926 & 0.84 & RI, MS \\
2 & $\alpha$-Pinene & 949 & Nd & RI, MS \\
3 & Sabinene & 974 & 0.72 & RI, MS \\
4 & Myrcene & 999 & 1.19 & RI, MS \\
5 & $p$-Cymene & 1024 & 2.39 & RI, MS \\
6 & Limonene & 1028 & 2.18 & RI, MS \\
7 & -3-Carene & 1030 & 3.37 & RI, MS \\
8 & 1,8-Cineole & 1035 & Nd & RI, MS \\
9 & $\gamma$-terpinene & 1075 & Nd & RI, MS \\
10 & Terpinolene & 1081 & 0.61 & RI, MS \\
11 & Dehydro linalool & & 1092 & 1.29 & RI, MS \\
12 & Linalool & 1097 & 3.46 & RI, MS \\
13 & Octen-3-yl-acetate & 1114 & 0.83 & RI, MS \\
14 & Myrcenol & 1121 & 1.16 & RI, MS \\
15 & 3-Octanol acetate & 1122 & 1.01 & RI, MS \\
16 & -1-Terpinoel & 1133 & 0.33 & RI, MS
\end{tabular}




\begin{tabular}{|c|c|c|c|c|}
\hline 17 & p-Cymene-8-ol & 1183 & 0.45 & RI, MS \\
\hline 18 & cis-pinocarvyl acetate & 1313 & 0.34 & RI, MS \\
\hline 19 & $\alpha$-longipinene & 1353 & 0.82 & RI, MS \\
\hline 20 & Nevyl acetate & 1364 & 0.68 & RI, MS \\
\hline 21 & Italicene & 1405 & 0.5 & RI, MS \\
\hline 22 & E-Caryophyllene & 1420 & 48.21 & RI, MS \\
\hline 23 & $\alpha$-Humulene & 1450 & 10.28 & RI, MS \\
\hline 24 & E- $\beta$-Farnesene & 1458 & 3.21 & RI, MS \\
\hline 25 & $\begin{array}{l}\text { 7-epi-1,2-dehydro } \\
\text { sesquicineol }\end{array}$ & 1471 & 0.72 & RI, MS \\
\hline 26 & $\gamma$-Muurolene & 1480 & 1.30 & RI, MS \\
\hline 27 & Epi- cubenol & 1493 & 0.39 & RI, MS \\
\hline 28 & $\alpha$-selinene & 1497 & 0.78 & RI, MS \\
\hline 29 & Spathulenol & 1577 & 6.73 & RI, MS \\
\hline 30 & Caryophyllen oxide & 1582 & 0.41 & RI, MS \\
\hline 31 & globulol & 1586 & 0.80 & RI, MS \\
\hline 32 & $\beta$-eudesmol & 1650 & 0.73 & RI, MS \\
\hline 33 & $\alpha$-bisabolol & 1684 & 4.25 & RI, MS \\
\hline 34 & $\beta$-Bisabolene & 1790 & $\mathrm{Nd}$ & RI, MS \\
\hline
\end{tabular}

$\mathrm{Nd}$ : Not detected, or amount of component is below $0.1 \%$.

Table 2 lists the yields, the growth stages, the fertility and infertility states, the compounds, and the chemical composition of the essential oil from the aerial parts of $P$. ferulacea, extracted by hydrodistillation. The highest oil yield was obtained at the flowering stage in the infertile individuals $(0.29 \% \mathrm{w} / \mathrm{w})$ by hydrodistillation.

In some essential oil compounds, significant differences were observed in the growth stage and in the type of individual treatments. Duncan's test was carried out to determine the composition parameters and means \pm standard error and also, to test the impact of the growth stage and the type of individual treatments on oil compounds (Tables 2 and 3). Furthermore, Figure 1 compared the percentage of the major components of $P$. ferulacea oils, extracted at different growth stages.

As can be seen in Table 2, some oil compositions of $P$. ferulacea were significantly affected $(\mathrm{p}<0.01)$ by the type of individuals at the flowering and seeding stages. At the flowering stage, a significant difference was observed between fertile and infertile plants for octen-3-yl acetate, myrcenol, 3-octanol acetate, 1-terpineol, cis-pinocarvyl acetate, and $\beta$-eudesmol; and also, at the seeding stage, for $\alpha$-thujene, myrcene, limonene, $\delta$-3-carene, $\gamma$-terpinene, italicene, $(\mathrm{E})$-caryophyllene, $(\mathrm{E})$ - $\beta$-farnesene, and caryophyllene oxide (Table 2). This difference may have been resulted from the existence of flowers and seeds in fertile plants. Akhgar et al. (2011) showed that the essential oil content and the chemical composition of $P$. ferulacea leaves is higher than fruits. 
Table 2. Oils component of Prangos ferulaceae (L.) Lindl at different growth stages and extraction methods

\begin{tabular}{|c|c|c|c|c|c|c|c|c|c|}
\hline \multirow[t]{2}{*}{ Compound } & \multirow{2}{*}{$\begin{array}{c}\text { Before } \\
\text { flowering }\end{array}$} & \multicolumn{4}{|c|}{ Flowering stage } & \multicolumn{4}{|c|}{ Seeding stage } \\
\hline & & Fertile & Infertile & Mean \pm SE & Significance & Fertile & Infertile & Mean \pm SE & Significance \\
\hline$\alpha$-Thujene & - & 1.1 & 0.84 & $0.97 \pm 0.12$ & $\mathrm{~ns}$ & 1.23 & 0.48 & $0.85 \pm 2.83$ & $*$ \\
\hline Sabinene & 0.53 & 0.73 & 0.72 & $0.72 \pm 0.03$ & ns & 1.44 & 1.09 & $1.26 \pm 0.15$ & ns \\
\hline Myrcene & 0.44 & 0.97 & 1.19 & $1.08 \pm 0.37$ & ns & 1.08 & 0 & $0.54 \pm 0.43$ & $*$ \\
\hline p-Cymene & 3.43 & 3.31 & 2.39 & $2.85 \pm 0.27$ & ns & - & - & - & - \\
\hline Limonene & 1.76 & 2.77 & 2.18 & $2.47 \pm 0.29$ & ns & 4.33 & 1.88 & $3.10 \pm 0.72$ & $*$ \\
\hline$\delta$-3-Carene & 0.87 & 3 & 3.37 & $3.18 \pm 0.30$ & $\mathrm{~ns}$ & 6.82 & 1.44 & $4.13 \pm 2.03$ & $*$ \\
\hline$\gamma$-terpinene & - & - & - & - & - & 0.96 & 0.63 & $0.79 \pm 0.15$ & $*$ \\
\hline Terpinolene & - & 0.7 & 0.61 & $0.65 \pm 0.16$ & ns & 1.05 & 1 & $1.02 \pm 0.28$ & ns \\
\hline Dehydro linalool & - & 1.45 & 1.29 & $1.37 \pm 0.16$ & ns & 1.74 & 1.4 & $1.57 \pm 0.44$ & ns \\
\hline Linalool & 1.30 & 3.18 & 3.46 & $3.32 \pm 0.67$ & ns & 0.35 & 0.31 & $0.33 \pm 0.03$ & ns \\
\hline Octen-3-yl-acetate & - & 0.21 & 0.83 & $0.52 \pm 0.18$ & $*$ & - & - & - & - \\
\hline Myrcenol & - & 0.24 & 1.16 & $0.7 \pm 0.27$ & $*$ & - & - & - & - \\
\hline 3-Octanol acetate & - & 0.21 & 1.01 & $0.61 \pm 0.25$ & $*$ & - & - & - & - \\
\hline -1-Terpinoel & - & 0.8 & 0.33 & $0.56 \pm 0.17$ & $*$ & - & - & - & - \\
\hline p-Cymene-8-ol & - & 0.53 & 0.45 & $0.49 \pm 0.09$ & ns & 1.77 & 0.87 & $1.32 \pm 0.40$ & $*$ \\
\hline $\begin{array}{l}\text { cis-pinocarvyl } \\
\text { acetate }\end{array}$ & - & 0 & 0.34 & $0.17 \pm 0.16$ & $*$ & 0.27 & 0.13 & $0.20 \pm 0.04$ & ns \\
\hline$\alpha$-longipinene & 0.22 & 0.74 & 0.82 & $0.78 \pm 0.20$ & ns & 0.28 & 0.14 & $0.21 \pm 0.04$ & ns \\
\hline Nevyl acetate & - & 0.68 & 0.68 & $0.68 \pm 0.12$ & ns & 0.69 & 0.54 & $0.61 \pm 0.06$ & ns \\
\hline Italicene & - & 0.66 & 0.5 & $0.58 \pm 0.05$ & $\mathrm{~ns}$ & 0.9 & 0.3 & $0.60 \pm 0.18$ & $*$ \\
\hline E-Caryophyllene & 33.13 & 42.49 & 48.21 & $45.35 \pm 2.58$ & $\mathrm{~ns}$ & 27.05 & 32.13 & $29.59 \pm 5.36$ & $*$ \\
\hline$\alpha$-Humulene & 8.34 & 8.87 & 10.28 & $9.57 \pm 0.49$ & ns & 3.34 & 2.91 & $3.12 \pm 0.36$ & ns \\
\hline
\end{tabular}




\begin{tabular}{|c|c|c|c|c|c|c|c|c|c|}
\hline E- $\beta$-Farnesene & 2.48 & 2.79 & 3.21 & $3.0 \pm 0.17$ & ns & 5.77 & 12.99 & $9.38 \pm 2.82$ & $*$ \\
\hline $\begin{array}{l}\text { 7-epi-1,2-dehydro } \\
\text { sesquicineol }\end{array}$ & 0.41 & 0.68 & 0.72 & $0.70 \pm 0.04$ & ns & 0.76 & 0.57 & $0.66 \pm 0.06$ & ns \\
\hline$\gamma$-Muurolene & - & 1.49 & 1.30 & $1.39 \pm 0.12$ & ns & 0.24 & 0.95 & $0.59 \pm 0.29$ & ns \\
\hline Epi- cubenol & - & 0.45 & 0.39 & $0.42 \pm 0.03$ & ns & - & - & - & - \\
\hline$\alpha$-selinene & 0.73 & 1.14 & 0.78 & $0.96 \pm 0.13$ & ns & - & - & - & - \\
\hline Spathulenol & 1.39 & 9.36 & 6.73 & $8.04 \pm 1.05$ & ns & 32.87 & 35.54 & $34.20 \pm 4.24$ & ns \\
\hline globulol & 1.16 & 0.91 & 0.80 & $0.85 \pm 0.13$ & ns & 2.2 & 2.29 & $2.24 \pm 0.25$ & ns \\
\hline$\beta$-eudesmol & 1.84 & 0.55 & 0.73 & $0.64 \pm 0.06$ & $*$ & - & - & - & - \\
\hline$\alpha$-bisabolol & 1.37 & 4.36 & 4.25 & $4.30 \pm 0.68$ & ns & - & - & - & - \\
\hline 1,8-Cineole & 1.02 & - & - & - & - & - & - & - & - \\
\hline$\alpha$-Pinene & 0.55 & - & - & - & - & - & - & - & - \\
\hline Total & & 94.84 & 99.98 & & & 98.08 & 99.18 & & \\
\hline $\begin{array}{l}\text { Oil yield } \\
(\% \mathrm{w} / \mathrm{w})\end{array}$ & 0.26 & 0.22 & 0.29 & - & - & 0.22 & 0.24 & - & - \\
\hline
\end{tabular}

Mean \pm SE: (Mean \pm Std. Error), ${ }^{*} \mathrm{P}<0.01$, ns: not significant 


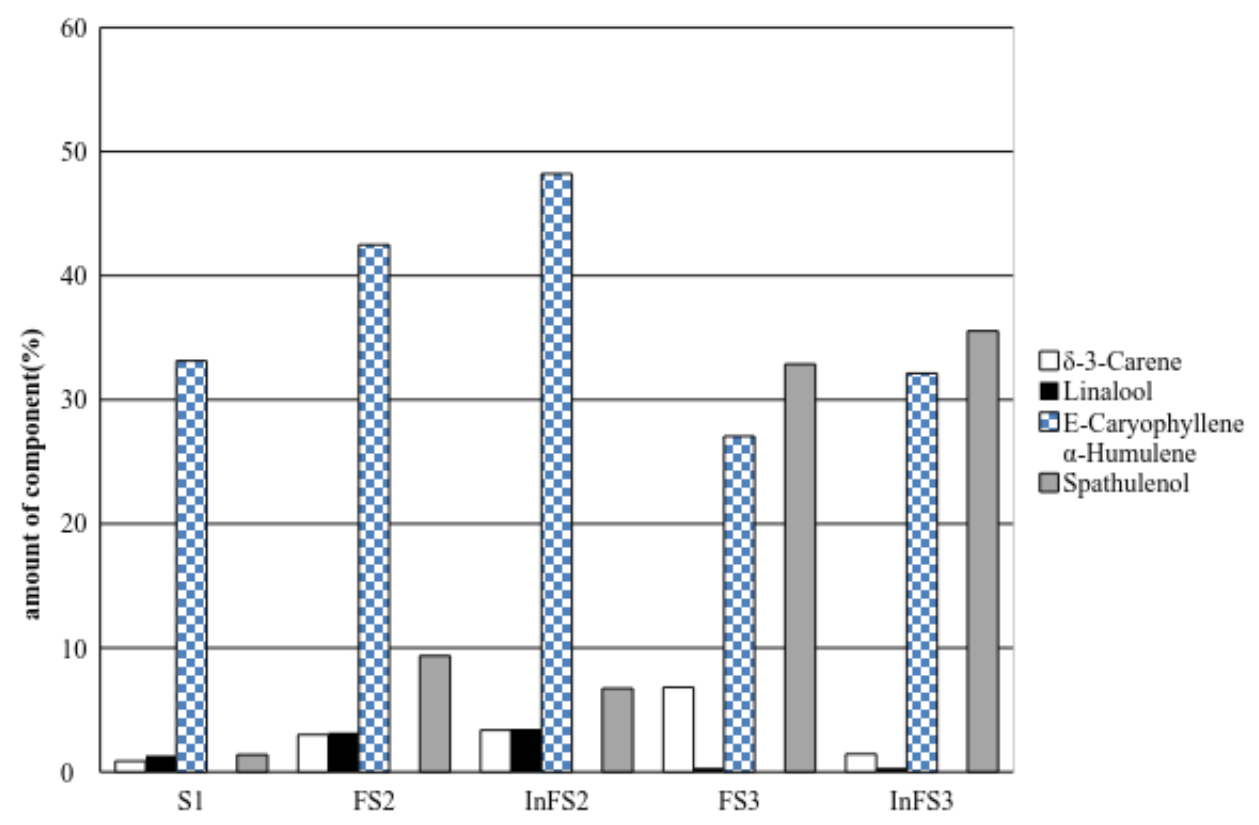

Figure 1. Comparison between amounts of the major components (\%) of P. ferulacea oils extracted at different growth stages. S1: before flowering (stage 1), FS2: the fertile plant in stage 2 or flowering, FS3: the fertile plant in stage 2 or seeding, InFS2: the infertile plant in stage 1, InFS2: the infertile plant in stage 2.

Table 3 revealed that in 26 components of fertile and 23 compounds of infertile individuals at two growth stages (flowering and seeding), significant differences have been observed. This finding indicates that the phenology factor can play an important role in determining the composition of oils.

Table 3. The chemical compositions (\%) of P. ferulacea (Mean \pm Std. Error) at flowering and seeding stages for fertile and infertile plants

\begin{tabular}{|c|c|c|c|c|c|c|}
\hline Compound & Fertile $^{\mathbf{F}}$ & Fertile $^{\mathbf{S}}$ & Significance & Infertile $^{\mathbf{F}}$ & Infertile $^{\mathbf{S}}$ & Significance \\
\hline$\alpha$-Thujene & 1.10 & 10.23 & $*$ & 0.84 & 0.48 & $\mathrm{~ns}$ \\
\hline Sabinene & 0.73 & 1.44 & $*$ & 0.72 & 1.09 & $*$ \\
\hline Myrcene & 0.97 & 1.08 & ns & 1.29 & 0 & $*$ \\
\hline p-Cymene & 3.31 & - & $*$ & 2.39 & - & $*$ \\
\hline Limonene & 2.77 & 4.33 & $*$ & 2.18 & 1.88 & ns \\
\hline$\delta$-3-Carene & 3.00 & 6.82 & $*$ & 3.37 & 1.44 & ns \\
\hline$\gamma$-terpinene & - & 0.96 & $*$ & - & 0.63 & $*$ \\
\hline Terpinolene & 0.70 & 1.05 & ns & 0.61 & 1.00 & ns \\
\hline Dehydro linalool & 1.45 & 1.74 & $\mathrm{~ns}$ & 1.29 & 1.40 & ns \\
\hline Linalool & 3.18 & 0.35 & $*$ & 3.76 & 0.31 & $*$ \\
\hline Octen-3-yl-acetate & 0.21 & - & $*$ & 0.83 & - & $*$ \\
\hline Myrcenol & 0.24 & - & $\mathrm{ns}$ & 1.16 & - & $*$ \\
\hline 3-Octanol acetate & 0.21 & - & ns & 1.01 & - & $*$ \\
\hline -1-Terpinoel & 0.80 & - & $*$ & 0.33 & - & $*$ \\
\hline
\end{tabular}




\begin{tabular}{|c|c|c|c|c|c|c|}
\hline p-Cymene-8-ol & 0.53 & 1.77 & $*$ & 0.45 & 0.87 & ns \\
\hline $\begin{array}{l}\text { cis-pinocarvyl } \\
\text { acetate }\end{array}$ & - & 0.27 & $*$ & 0.54 & 0.13 & $*$ \\
\hline$\alpha$-longipinene & 0.74 & 0.28 & ns & 0.92 & 0.14 & $*$ \\
\hline Nevyl acetate & 0.68 & 0.69 & ns & 0.68 & 0.54 & ns \\
\hline Italicene & 0.66 & 0.90 & $*$ & 0.5 & 0.30 & ns \\
\hline E-Caryophyllene & 40.49 & 27.05 & $*$ & 48.21 & 40.13 & ns \\
\hline$\alpha$-Humulene & 8.87 & 3.34 & $*$ & 10.38 & 2.91 & $*$ \\
\hline E- $\beta$-Farnesene & 2.79 & 5.77 & $*$ & 3.21 & 14.99 & $*$ \\
\hline $\begin{array}{l}\text { 7-epi-1,2-dehydro } \\
\text { sesquicineol }\end{array}$ & 0.68 & 0.76 & ns & 0.72 & 0.57 & ns \\
\hline$\gamma$-Muurolene & 1.49 & 0.24 & $*$ & 1.30 & 0.95 & ns \\
\hline Epi- cubenol & 0.45 & - & $*$ & 0.39 & - & $*$ \\
\hline$\alpha$-selinene & 1.14 & - & $*$ & 0.88 & - & $*$ \\
\hline Spathulenol & 9.36 & 33.87 & $*$ & 6.83 & 41.54 & $*$ \\
\hline $\begin{array}{l}\text { Caryophyllen } \\
\text { oxide }\end{array}$ & 0.47 & 3.94 & $*$ & 0.41 & 1.59 & $*$ \\
\hline globulol & 0.91 & 2.20 & $*$ & 0.80 & 2.29 & $*$ \\
\hline$\beta$-eudesmol & 0.55 & - & $*$ & 0.73 & - & $*$ \\
\hline$\alpha$-bisabolol & 4.36 & - & $*$ & 4.25 & - & $*$ \\
\hline
\end{tabular}

$* \mathrm{P}<0.01$, ns: not significant, F: flowering, S: seeding

Optimization of hydrodistillation and steam distillation methods for the other plant species has been previously studied. Table 4 exhibits the summary of the number and concentrations of the components present in the volatile fractions, obtained by the HD and SD. There are evident differences between the percentage and the number of components, as follows: HD: $99.98 \%$ and 30, and SD: $94.87 \%$ and 23 . The yield of volatile components of $P$. ferulacea obtained by use of the HD $(0.29 \%)$ was higher than the SD $(0.17 \%)$. This result is consistent with the findings of Kiran et al. (2005) and Sefidkon et al. (2007). The main components of these extractions were (E)caryophyllene (48.21-52.26\%), $\alpha$-humulene (3.97-10.28\%), spathulenol (6.73-10.37\%), linalool (0.51-3.18\%), and $\delta$-3-carene (1.31-3.37\%), among which the amounts of $\alpha$ humulene and spathulenol were higher in the SD method than the HD method.

Table 4. Comparative chemical composition of P. ferulacea oil at flwering stage of plant growth by HD and SD methods

\begin{tabular}{l|c|c}
\hline \multicolumn{1}{c|}{ Compound } & $\begin{array}{c}\text { Flowering stage } \\
(\boldsymbol{\%})\end{array}$ \\
\hline & hydro-distillation(HD) & Steam distillation (SD) \\
\hline$\alpha$-Thujene & 0.84 & - \\
Sabinene & 0.72 & 0.49 \\
Myrcene & 1.19 & 0.69 \\
p-Cymene & 2.39 & - \\
Limonene & 2.18 & 0.51 \\
$\delta$-3-Carene & 3.37 & 1.31 \\
\hline
\end{tabular}




\begin{tabular}{l|c|c}
\hline$\gamma$-terpinene & - & 0.49 \\
Terpinolene & 0.61 & 0.86 \\
Dehydro linalool & 1.29 & 1.25 \\
Linalool & 3.46 & 0.56 \\
Octen-3-yl-acetate & 0.83 & - \\
Myrcenol & 1.16 & - \\
3-Octanol acetate & 1.01 & - \\
-1-Terpinoel & 0.33 & - \\
p-Cymene-8-ol & 0.45 & - \\
cis-pinocarvyl acetate & 0.34 & - \\
$\alpha$-longipinene & 0.82 & - \\
Nevyl acetate & 0.68 & 0.91 \\
Italicene & 0.5 & 0.70 \\
E-Caryophyllene & 48.21 & 52.26 \\
$\alpha$-Humulene & 10.28 & 3.97 \\
E- $\beta$-Farnesene & 3.21 & 5.01 \\
7-epi-1,2-dehydro sesquicineol & 0.72 & 1.05 \\
$\gamma$-Muurolene & 1.30 & 1.54 \\
Epi-cubenol & 0.39 & 0.75 \\
$\alpha$-selinene & 0.78 & 0.49 \\
Spathulenol & 6.73 & 10.37 \\
Caryophyllen oxide & 0.41 & 0.61 \\
globulol & 0.80 & 0.52 \\
$\beta$-eudesmol & 0.73 & 3.46 \\
$\alpha$-bisabolol & 4.25 & 5.26 \\
$\gamma$-himachalene & - & 1.81 \\
\hline Total & 99.98 & 94.87 \\
& 0.29 & 0.17 \\
\hline
\end{tabular}

\section{Conclusions}

According to the performed study, it can be concluded that based on the certain analyses of phenology and physiology, extending the extraction method can definitely increase the quality and quantity of the extracted essential oil of $P$. ferulacea.

On the basis of the findings, it can be suggested that the infertile individual at the flowering stage is a good sample for a comprehensive analysis of volatile compounds in $P$. ferulacea and can strongly enhance the quality of commercial oils. Moreover, while the SD and HD methods are relatively proper techniques for the quantitative analysis of volatile components, but it should be declared that extensive works are still required in order to adopt them for qualitative analysis.

Achnowlegments. This work was supported by Iran National Science Foundation Science deputy of presidency (INSF). 


\section{REFERENCES}

[1] Adams, R. P. (2007): Identification of Essential Oils Components by Gas Chromatography/Quadrupole Mass Spectroscopy. - Allured Publishing Corporation, Illinois.

[2] Akhgar, M., Pahlavanzadeh, S., Lotfi-Anari, P., Faghihi-Zarandi, A. (2011): Composition of essential oils of fruits and leaves of Prangos ferulacea (L.) Lindl. growing wild in Iran. - J. TMC 1(1): 1-4.

[3] Amiri, H. (2007): Essential oil variation of Prangos ferulacea Lindl. in different stages of plant growth. - Iran. J. Med. Arom. Plants Res. 23: 55-60.

[4] Ayres, D., Tamm, C., Raphael, R., Shamma, M. (1994): Dictionary of natural products. Chapman \& Hall, London.

[5] Baser, K. H., Ermin, N., Adiguzel, N., Aytac, Z. (1996): Composition of the essential oil of Prangos ferulaceae . J. Essent. Oil Res 8: 297-298.

[6] Coskun, B., Gulsen, N., Umucalilar, H. D. (2004): The nutritive value of Prangos ferulacea. - Grass and Forage Science 59: 15-9.

[7] Eshbakova, K. A., Saidkhodzhaev, A. I., Baser, K. H. C., Duman, H., Vdovin, A. D., Abdullaev, N. D. (2006): Furocoumarins from Prangos ferulacea. - Chemistry of Natural Compounds 42 (1):102-103.

[8] Faborode, M. O. (1996): Identification and significance of the oil-point in seed-oil expression. - J. Agricultural Engineering Research 65(4): 335-345.

[9] Gheitoori, M., Malakpoor, B., Jafari, M., Jalili, A. (1997): Investigation of ecological characteristic of Prangos spp. in Kermanshah province. - J. Pajohesh and Sazandegi 32(3): 32-35.

[10] Hay, R. K. M. (1993): Physiology. - In: Hay, R. K. M., Waterman, P. G. (eds.) Volatile oil crops: their biology, biochemistry and production. Longman Scientific \& Technical Press, Harlow, 23-46.

[11] Hay, R. K. M., Svoboda, K. P. (1993): Botany. - In: Hay, R. K. M., Waterman, P. G. (eds.) Volatile oil crops: their biology, biochemistry and production. Longman Scientific \& Technical Press, Harlow, 5-22.

[12] Jordan, M. J., Laxa, V., Rota, M. C., Loran, S., Sotomayor, J. A. (2013): Effect of the phenological stage on the chemical composition, and antimicrobial and antioxidant properties of Rosmarinus officinalis L. essential oil and its polyphenolic extract. Industrial Crops and Products 48: 144-152.

[13] Kiran, G. D., Babu, V., Kaul, K. (2005): Variation in essential oil composition of rosescented geranium (Pelargonium sp.) distilled by different distillation techniques. Flavour and Fragrance Journal 20(2): 222-231.

[14] Kuznetsova, G., Yur'ev, Y. N., Kuzmina, L., Senchenko, G., Shagova, L. (1973): Essential oil composition of fruit of some species of Prangos. - Rast Resur 9(3): 388391.

[15] Lawrence, B. M. (2002): Commercial essential oils: Truths and consequences. - In: Swift, K. A. D. (ed.), Royal Society of Chemistry RSC, Cambridge Press, 57-83.

[16] Marotti, M., Piccaglia, R., Giovanelli, E., Deans, S. G., Eaglesham, E. (1994): Effects of variety and ontogenic stage on the essential oil composition and biological activity of fennel (Foeniculum vulgare Mill.). - J. Essent Oil Research 6(1): 57-62.

[17] Massumi, M., Fazeli, M., Alavi, S., Ajani, Y. (2007): Chemical constituents and antibacterial activity of essential oil of Prangos ferulacea (L.) Lindl. fruits. - Iran J. Pharm. Science 3(3): 171-176.

[18] Mohammadi, J., Zare, T. (2013): Hypoglycemic action of Prangos ferulacea in normal and streptozotocin induced diabetic Wistar rats. - J. American Science 9(10): 51-54

[19] Ramesh, B., Pugalendi, K. V. (2005): Antihyperlipidemic and antidiabetic effects of umbelliferone in streptozotocin diabetic rats. - Yale J. Bio \& Med 78(4): 189-96. 
[20] Razavi, S. M. (2011): Chemical composition and some allelopathic aspects of essential oils of (Prangos ferulacea L.) Lindl at different stages of growth. - J. Agriculture Science and Technology 14(2): 349-356.

[21] Razavi, S. M. (2012): Phenolic compounds from the aerial parts of Prangos ferulaceae, with antioxidant activity. - EurAsian J. BioSciences 6(1): 91-96.

[22] Razavi, S. M., Hajiboland, R. (2009): Dormancy breaking and germination of Prangos ferulaceae seeds. - EurAsian J. BioSciences 3(11): 78-83.

[23] Rechinger, K. H. (1987): Prangos. - Flora Iranica Umbelliferae 162: 196.

[24] Reuther, K. (2013): Spatial and temporal flower presentation in Apiacea-Apioideae. Dissertation, Department of Biology, The Johannes Gutenberg University.

[25] Sadraei, H., Shokoohinia, Y., Sajjadi, S. E., Ghadirian, B. (2012): Antispasmodic effect of osthole and Prangos ferulacea extract on rat uterus smooth muscle motility. Research Pharm Science 7(3): 141-149.

[26] Sajjadi, S. E., Shokoohinia, Y., Gholamzadeh, S. (2011): Chemical composition of essential oil of Prangos ferulacea (L.) Lindl. roots. - J. Chemija 22(3): 178-80.

[27] Sefidkon, F., Abbasi, Kh., Jamzad, Z., Ahmadi, Sh. (2007): The effect of distillation methods and stage of plant growth on the essential oil content and composition of Saturejare chingeri Jamzad. - J. Food Chemistry 100: 1054-1058.

[28] Sefidkon, F., Khajavi, M., Malackpour, B. (1998): Analysis of the oil of of Prangos ferulacea (L.) Lindl. - J. Essential Oil Research 10(1): 81-2.

[29] Sellami, I. H., Maamouri, E., Chahed, T., Wannes, W. A., Kchouk, M. E., Marzouk, B. (2009): Effect of growth stage on the content and composition of the essential oil and phenolic fraction of sweet marjoram (Origanum majorana L.). - Industrial Crops and Products 30(3): 395-402.

[30] Soltani band, K., Kafash Farkhad, N., Farokhi, F., Togmechi, A. (2012): Effects of hydroalcoholicextract of Prangos ferulacea (L.) Lindle on histopathology of pancreas and diabetes treatmentin STZ- induced diabetic rats. - Avicenna J Phytomed 2(1): 31-8.

[31] SPSS, SPSS for Windows. (1993): Release 6.0. - Chicago, IL, USA, SPSS Inc. 